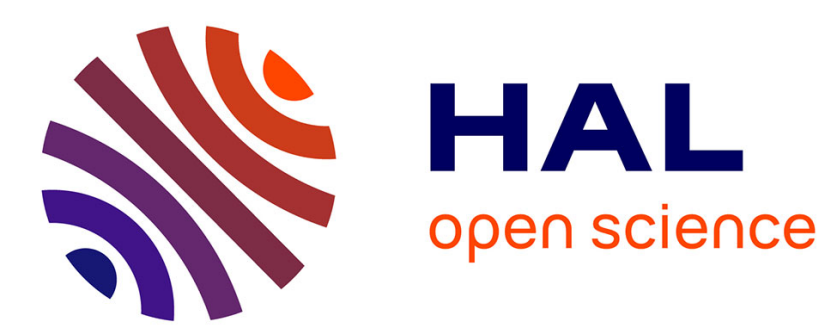

\title{
THE APPLICATION OF HYPERFINE INTERACTIONS IN BIOLOGY
}

\author{
C. A. Johnson
}

\section{To cite this version:}

C. A. Johnson. THE APPLICATION OF HYPERFINE INTERACTIONS IN BIOLOGY. Journal de Physique Colloques, 1974, 35 (C1), pp.C1-57-C1-63. 10.1051/jphyscol:1974120 . jpa-00215495

\section{HAL Id: jpa-00215495 https://hal.science/jpa-00215495}

Submitted on 1 Jan 1974

HAL is a multi-disciplinary open access archive for the deposit and dissemination of scientific research documents, whether they are published or not. The documents may come from teaching and research institutions in France or abroad, or from public or private research centers.
L'archive ouverte pluridisciplinaire HAL, est destinée au dépôt et à la diffusion de documents scientifiques de niveau recherche, publiés ou non, émanant des établissements d'enseignement et de recherche français ou étrangers, des laboratoires publics ou privés. 


\title{
THE APPLICATION OF HYPERFINE INTERACTIONS IN BIOLOGY
}

\author{
C. E. JOHNSON \\ Oliver Lodge Laboratory, University of Liverpool, \\ Liverpool, L $693 \mathrm{BX}$, England
}

\begin{abstract}
Résumé. - L'application des spectres Mössbauer à l'étude de l'état des atomes de fer dans les molécules biologiques est décrite. Le déplacement chimique, quand il est bien calibré, permet de déterminer l'état d'oxydation du fer. Le couplage magnétique hyperfin est même plus sensible à l'état du fer et, pour les protéines fer-soufre, fournit une preuve directe que les groupes d'atomes de fer sont fortement couplés antiferromagnétiquement.
\end{abstract}

\begin{abstract}
The application of Mössbauer spectra to the study of the state of iron atoms in biological molecules is described. The chemical shift when suitably calibrated enables the oxidation state of the iron to be determined. The magnetic hyperfine coupling is even more sensitive to the state of the iron and for iron-sulphur proteins provides direct evidence that groups of iron atoms are strongly coupled together antiferromagnetically.
\end{abstract}

1. Introduction. - Many biological molecules contain iron. Since the Mössbauer Effect provides a powerful probe of the chemical state and the environment of iron atoms, it is clear that it can be a useful tool to be applied to the study of proteins and enzymes. Indeed the first measurements of the Mössbauer spectrum of $\mathrm{Fe}^{57}$ in haemin were reported by Gonser [1] at the International Conference on the Mössbauer Effect in Paris in 1961, only four years after the appearance of Mössbauer's papers on the discovery of the effect.

The electronic changes which take place during a biochemical reaction are generally centred around the iron atoms. Hence the iron plays a very important role in biology, and not only is it interesting to the physicist to be able to study iron in an unfamiliar environment, but the results may be of real value to the biochemist in trying to understand the nature of the reactions in which the molecule is involved in the living cell.

The main groups of biological molecules which contain iron at their active centres are shown in table I.

The haem proteins are the best understood of these molecules, and the first systematic study of biological molecules using the Mössbaluer Effect was done on them by Lang and Marshall [2]. Their molecular structure is known from X-ray diffraction measurements. The iron atoms are octahedrally co-ordinated to four nitrogen atoms in the haem group and to a fifth nitrogen in a histidine group which formed the link to the chain of amino-acids. The sixth ligand may be varied. and the state of the iron atom varies with it. Previous studies of the iron had been made by magnetic susceptibility and EPR techniques. In healthy blood the iron is ferrous, being low-spin when oxygenated and high-spin when de-oxygenated. Some ligands make the iron ferric, e. g. fluoride (high-spin) or cyanide (low-spin). The Mössbauer spectra of these molecules have been valuable in confirming these earlier conclusions, and have yielded quantitative datal on the way that the energy levels and wave functions of the iron atoms are affected by the ligand field and spin-orbit coupling in the protein. They have also been valuable in providing standard spectra for each of the four common states of iron, and hence in establishing on a firm basis the use of Mössbaluer spectroscopy as a way of obtaining information about iron in a biological (e. g. haem) environment. More recent work [3] has been directed towards the study of new haem derivatives, and the use of the Mössbauer spectrum to investigate the products of biochemical reactions. A review of work on haem proteins has been given by Lang [4].

Most of the rest of the Mössbauer work on biological molecules has been done on the iron-sulphur proteins. Unlike the haem proteins, little structural information is available on these molecules. The structure has only recently been determined for three of them. These are a rubredoxin, a ferredoxin (bacterial) - both from Clostridium Pastemrianum - and a high potential iron protein (HIPIP) from Chromatium. Although these molecules are different in size, structure and function, they all contain iron atoms in similar environments with the iron at the centre of four sulphur atoms which form an approximate tetrahedron. The simplest of these molecules 


\section{TABLE I}

Some proteins which contain iron

\begin{tabular}{|c|c|c|c|}
\hline \multicolumn{4}{|c|}{ Iron proteins } \\
\hline haemoproteins & & & $\begin{array}{l}\text { iron storage } \\
\text { and transport } \\
\text { proteins }\end{array}$ \\
\hline $\begin{array}{l}\text { haemoglobin } \\
\text { myoglobin } \\
\text { cytochromes } \\
\text { peroxidases } \\
\text { catalases }\end{array}$ & & & $\begin{array}{l}\text { ferritin } \\
\text { transferrins } \\
\text { haemosiderin }\end{array}$ \\
\hline $\begin{array}{l}\text { rubredoxins } \\
\text { (1-iron) }\end{array}$ & $\begin{array}{l}\text { ferredoxins } \\
\text { a) plant-type } \\
\text { (2-iron) } \\
\text { b) bacterial } \\
\text { (8-iron) }\end{array}$ & $\begin{array}{l}\text { high-potential } \\
\text { iron proteins } \\
\text { (4-iron) }\end{array}$ & $\begin{array}{l}\text { conjugated } \\
\text { iron-sulphur } \\
\text { proteins } \\
\text { ( } 8 \text { or more irons) }\end{array}$ \\
\hline
\end{tabular}

xanthine oxidase, etc.

are the rubredoxins, as they contain only one ironsulphur group per molecule. Next in order of complexity are the plant ferredoxins and hydroxylase proteins (adrenodoxin and putidaredoxin), which contain two iron atoms per molecule which are close to each other and are strongly interacting magnetically. More complex still are the bacterial ferredoxins and HIPIPs; in these the iron appears to be in units containing four iron atoms which are strongly coupled together magnetically. Tsibris and Woody [5] have reviewed the physical data, including Mössbauer spectra, which have been obtained on the iron-sulphur proteins.

In this paper we shall mainly describe the use of the Mössbauer Effect in the study of the iron-sulphur proteins. From a study of the 1 -iron protein rubredoxin in the oxidized and reduced states, the chemical shifts and magnetic hyperfine interaction of $\mathrm{Fe}^{2+}$ and $\mathrm{Fe}^{3+}$ in tetrahedral sulphur co-ordination are measured. This effectively calibrates these quantities, i. e. it allows for the effects of covalency of the irons in this environment. These single-iron data are then used in the interpretation of the data on the twoiron proteins. Here the magnetic moments of the two iron atoms in the molecule are found to be antiferromagnetically coupled together, and the resulting hyperfine spectrum is very different from those usually observed from a single iron atom. This is a situation unlike that found in inorganic complexes of iron, and it is not easy by any other method to observe directly the antiferromagnetic coupling between the pairs of iron atoms. Thus the Mössbauer Effect has been able to make a very real contribution to our knowledge of the iron-sulphur proteins.
2. Mössbauer spectroscopy. - The Mössbauer Effect has become well established as a powerful tool for probing the electronic charge and spin densities in solids. It has taken its place along with other spectroscopic techniques (NMR, EPR, optical and infra-red spectroscopy, ESCA, etc.), as a means of obtaining information on electronic structure and bonding. Like all these methods it was first applied to problems in physics and chemistry, and as understanding of the spectra and confidence in their interpretation developed, its extension to applications in biology eventually followed.

The measurements are usually made on frozen aqueous solutions of the proteins. The molecules are generally enriched in $\mathrm{Fe}^{57}$, although some measurements have been done using naturally occurring iron. The $\mathrm{Fe}^{57}$ may be incorporated in the molecule in either of two ways; either by growing the organism from which the protein is extracted on the separated isotope $\mathrm{Fe}^{57}$, or by incorporating it by chemical exchange. The growing method requires more $\mathrm{Fe}^{57}$, but it is more reliable and more generally applicable than exchange, which must be tested carefully to ensure that the protein is not modified by the process.

The Mössbauer spectrum is essentially a property of the Mössbauer nuclei (i. e. the $\mathrm{Fe}^{57}$ ) and so gives information local to the iron atoms in the protein. Conventional physical and chemical methods for studying the state of iron atoms are often difficult of apply because of the small number of these atoms compared with the total number of atoms in a biological molecule. 
Each of three main features of the Mössbauer spectrum :

(a) The chemical shift;

(b) The quadrupole splitting;

(c) The magnetic hyperfine splitting;

gives different and independent information about the electrons of the iron, and is sensitive to small details of the electron wave functions, especially the magnetic hyperfine structure. The use of these quantities is of course the same in principle in biological molecules or in inorganic complexes, but because of the effects of covalency the emphasis may be different, and we compare first some experimental data typical of the different type of compounds.

(a) Chemical shift. - Although the chemical shift depends upon the oxidation state and degree of covalency of the iron, it is not always possible to use them unambiguously to measure the oxidation state in proteins. There is no general theory of the chemical shift, and an empirical calibration of it is not always easy. However, in many cases the shift does give a good guide to the state of the iron, as many be seen from the data listed in table II.

It is seen that the shift decreases as the degree of covalency of the ligands increases, $i$. e. in the order $-\mathrm{H}_{2} \mathrm{O},-\mathrm{Cl}^{-},-\mathrm{O}^{2-},-\mathrm{N}^{3-},-\mathrm{S}^{2-},-\mathrm{CN}^{-}$, etc. Also it is systematically less by about $0.2 \mathrm{~mm} / \mathrm{s}$ for tetrahedral co-ordination compared with octahedral coordination to the same ligands. It is clear that the chemical state cannot be inferred from the value of the chemical shift alone. A possible exception might be high spin $\mathrm{Fe}^{2+}$ which usually has a large positive value of shift, but table II shows that it can be as low as $0.6 \mathrm{~mm} / \mathrm{s}$ in tetrahedral sulphur co-ordination, which overlaps with the values found for $\mathrm{Fe}^{3+}$ in other compounds.

(b) Quadrupole splitting. - This is mainly a measure of the local structure and symmetry in the region of the iron atom. It may also sometimes help to confirm the oxidation state of the atom. The sign of the splitting may enable the orbital wave function of the d-electrons to be determined. and may be used to deduce the nature of the distortion of the neighbouring atoms from cubic symmetry.

(c) Magnetic hyperfine splitting. - This is most sensitive to the state of the iron atom and can be very powerful. It may be observed for $\mathrm{Fe}^{3+}$ atoms at low temperatures where the electron spin relaxation times are long. For $\mathrm{Fe}^{2+}$ atoms the electron spin-lattice relaxation time is short and it is necessary to apply a strong magnetic field at low temperatures in order to observe magnetic splittings. The magnetic hyperfine interaction is a tensor quantity, and when its anisotropy can be measured it enables (as does the sign of the quadrupole splitting) the orbital wave function of the iron d-electrons to be determined.

While the chemical shift may provide a valuable clue to the state of the iron, measurements of magnetic hyperfine coupling are especially valuable in biological compounds since they are generally more sensitive to the finer details of the electronic state of the iron atoms.

3. Magnetic HFS in iron-sulphur proteins. 3. I I-IRON PROTEINS (RUBREDOXINS). - (a) Oxidized. The Mössbauer spectrum of oxidized rubredoxin at $4.2 \mathrm{~K}$ is shown in figure 1 and is a six-line $\mathrm{Fe}^{3+}$ pattern with an effective field of $-370 \mathrm{kOe}$ [6], [7]. The hyperfine spectrum is observed because of the long electron spin relaxation times and arises because the distorted tetrahedral ligand field is of the form $D\left(S_{z}^{2}-35 / 12\right)$ which splits the energy levels of the ion so that the ground state $\left|S_{z}= \pm 5 / 2\right\rangle$ is the only one populated at liquid helium temperatures. Since $g_{\|}$for this state is 9.4 , the hyperfine field $H_{\mathrm{n}}\left(\mathrm{Fe}^{3+}\right)$

\section{TABLE II}

Chemical shifts for several inorganic and biological molecules (in $\mathrm{mm} / \mathrm{s}$, measured at $77 \mathrm{~K}$ relative to iron metal at $290 \mathrm{~K}$ )

\begin{tabular}{|c|c|c|c|c|}
\hline Ligands & \multicolumn{2}{|r|}{$\mathrm{Fe}^{2+}$} & & $\mathrm{Fe}^{3+}$ \\
\hline $6 \mathrm{H}_{2} \mathrm{O}$ & $\mathrm{FeSiF}_{6} \cdot 6 \mathrm{H}_{2} \mathrm{O}$ & 1.42 & $\mathrm{Fe}_{2} \mathrm{O}_{3}$ & 0.50 \\
\hline $4 \mathrm{O}^{2-}$ & $\mathrm{FeBaSi}_{4} \mathrm{O}_{10}$ & 0.87 & 25 & 一 \\
\hline $6 \mathrm{Cl}^{-}$ & $\mathrm{FeCl}_{2}$ & 1.20 & $\mathrm{FeCl}_{3}$ & 0.53 \\
\hline $4 \mathrm{Cl}^{-}$ & $\left(\mathrm{NMe}_{4}\right)_{2} \mathrm{FeCl}_{4}$ & 1.05 & $\left(\mathrm{NMe}_{4}\right) \mathrm{FeCl}_{4}$ & 0.30 \\
\hline $\begin{array}{c}5 \mathrm{~N}, \mathrm{H}_{2} \mathrm{O} \\
\text { or } \mathrm{O}_{2}\end{array}$ & deoxyhaemoglobin & 0.90 & methaemoglobin & 0.20 \\
\hline $6 \mathrm{~S}^{2-}$ & - & - & Fe-tris-dtc & 0.50 \\
\hline$S^{2-}$ & rubredoxin & 0.65 & rubredoxin & 0.25 \\
\hline & ferredoxin (plant) & 0.56 & ferredoxin (plant) & 0.22 \\
\hline & adrenodoxin & - & adrenodoxin & 0.26 \\
\hline & reduced HIPIP & $0.42(*)$ & oxidized HIPIP & $0.32(*)$ \\
\hline & reduced ferredoxin (bacterial) & $0.58(*)$ & oxidized ferredoxin (bacterial) & $0.43(*)$ \\
\hline
\end{tabular}

(*) Average value. 


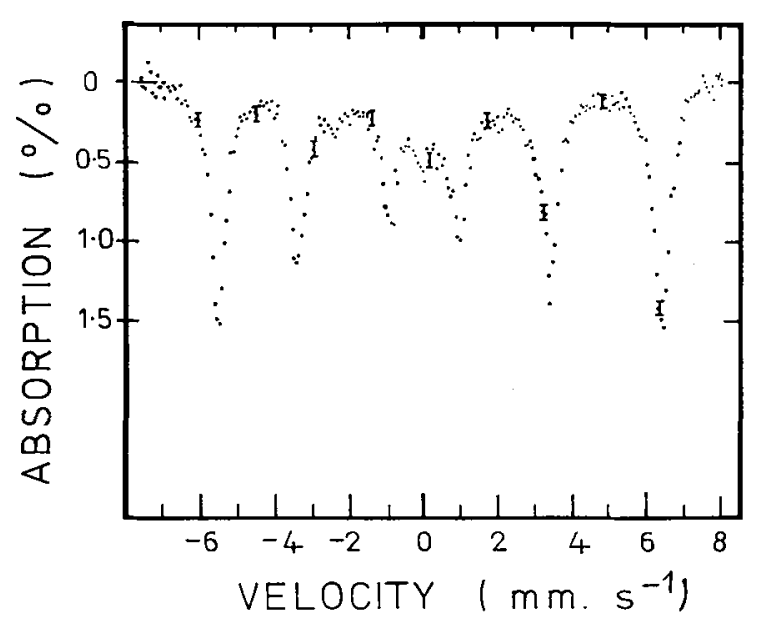

FIG. 1. - Mössbauer spectrum of oxidized rubredoxin at $4.2 \mathrm{~K}$. The hyperfine field of $\mathrm{Fe}^{3+}$ in a tetrahedral sulphur environment is $-375 \mathrm{kOe}$.

is $-395 \mathrm{kOe}$. In $\mathrm{Fe}_{2} \mathrm{O}_{3}$ it is $-550 \mathrm{kOe}$; in ferric tris-pyrrolidyldithiocarbamate, which has octahedral sulphur co-ordination, it is $-475 \mathrm{kOe}$. The low value in rubredoxin shows that the iron has strong covalent bonds to the sulphur ligands. The quadrupole splitting is positive. It arises from the asymmetry of the charges on the sulphur ligands, and shows that they are distorted by a compression along the symmetry (z) axis.

(b) Reduced. - The Mössbauer spectra of reduced rubredoxin at $4.2 \mathrm{~K}$ for several values of applied magnetic field are shown in figure 2 [7]. They are characteristic of $\mathrm{Fe}^{2+}$. In zero field there is a large quadrupole splitting $(3.3 \mathrm{~mm} / \mathrm{s})$ and a shift $(0.65 \mathrm{~mm} / \mathrm{s})$ which is low for $\mathrm{Fe}^{2+}$ but which is entirely consistent with tetrahedral sulphur ligands. Magnetic

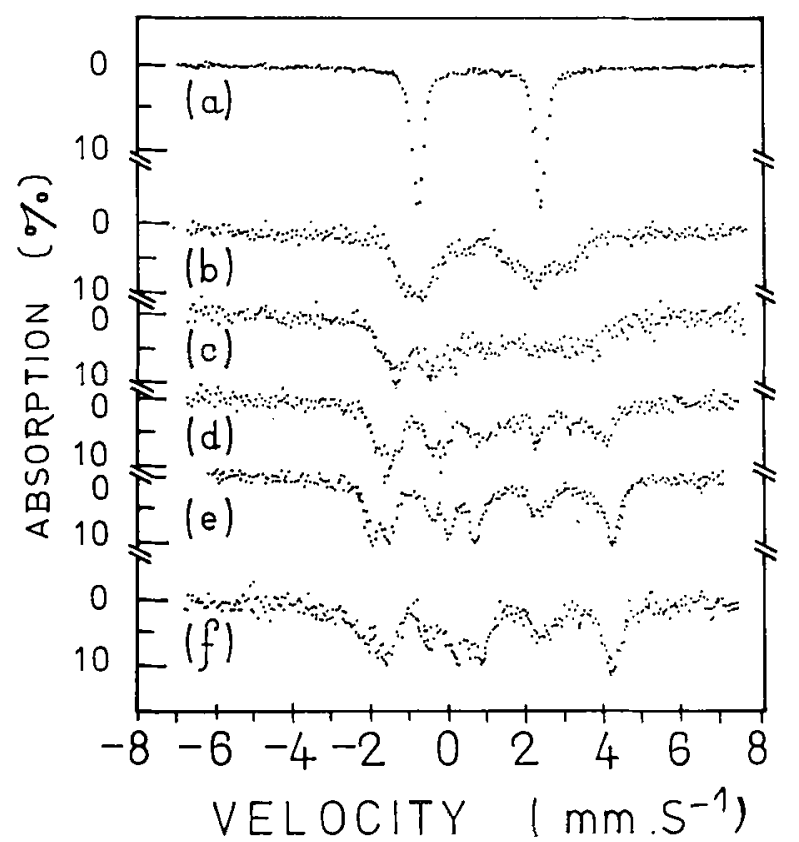

Fig. 2. - Mössbauer spectra of reduced rubredoxin at $4.2 \mathrm{~K}$ in magnetic fields of $(a) 0 \mathrm{kOe} ;(b) 5 \mathrm{kOe} ;(c) 10 \mathrm{kOe} ;(d) 15 \mathrm{kOe}$; (e) $30 \mathrm{kOe}$ and $(f) 60 \mathrm{kOe}$. hyperfine splitting is observed when large fields (up to $60 \mathrm{kOe}$ ) are applied and the effective field at the nuclei is predominantly perpendicular to the symmetry axis of the ligand field, so that

$$
H_{\text {eff }}=H+H_{\mathrm{nx}} \text {. }
$$

The internal field $H_{\mathrm{nx}}$ is plotted as a function of the applied field $H$ in figure 3 . The saturated value of the hyperfine field $H_{n x}\left(\mathrm{Fe}^{2+}\right)$ is estimated to be -210 kOe.

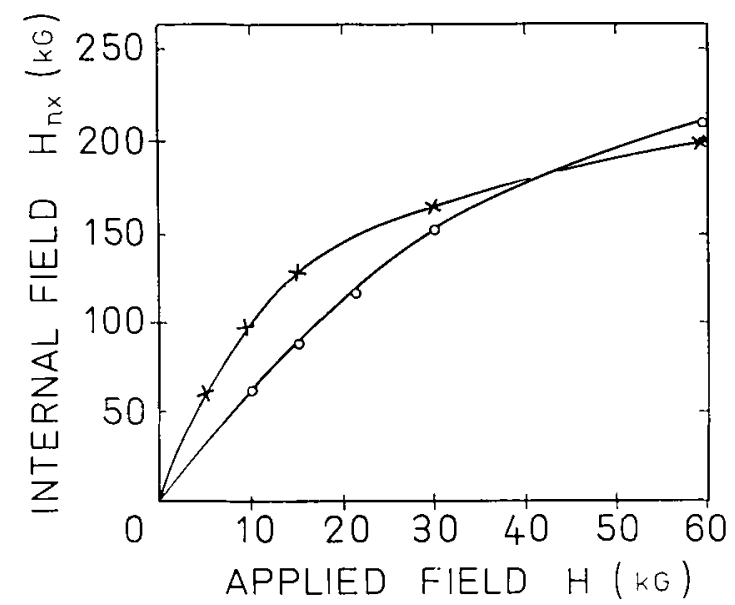

FIG. 3. - Internal magnetic fields in reduced rubredoxin $(\because)$ and in ferrous fluosilicate $(O)$ as a function of the applied magnetic field. By extrapolation to large fields, the hyperfine field of $\mathrm{Fe}^{2+}$ in a tetrahedral sulphur environment is about $-210 \mathrm{kOe}$.

These spectra are qualitatively similar to these observed [8] for polycrystals of ferrous fluosilicate which are shown in figure 4 . This is a well understood salt, with $H_{\mathrm{nx}}(0)=-248 \mathrm{kOe}$, and an axial ligand field splitting given by $D\left(S_{z}^{2}-2\right)$, where $D=+10.9 \mathrm{~cm}^{-1}$. The values of the internal field are compared with those in rubredoxin in figure 3 . It may be seen that although the saturated value of the hyperfine field is smaller for the rubredoxin, the values for small applied fields are larger than for ferrous fluosilicate. Assuming axial symmetry the internal field for small applied fields $\left(g_{\perp} \beta H \ll D\right)$ is given by

$$
H_{\mathrm{nx}}=\frac{3 g_{\perp} \beta H}{D} H_{\mathrm{nx}}\left(\mathrm{Fe}^{2+}\right) .
$$

A comparison with the fluosilicate data shows that in reduced rubredoxin, $D \simeq+4.4 \mathrm{~cm}^{-1}$. This is an approximate value of course, as non-axial ligand field splittings have been neglected.

The sign of the quadrupole coupling is seen to be negative, which shows that the ground state of the $\mathrm{Fe}^{2+}$ ion is $d_{z z}$, and hence that the sulphur tetrahedron is distorted by a compression along the $z$-axis. The observed value for the hyperfine field may be understood using the approach of Marshall and Johnson [9]. The core polarization field for 


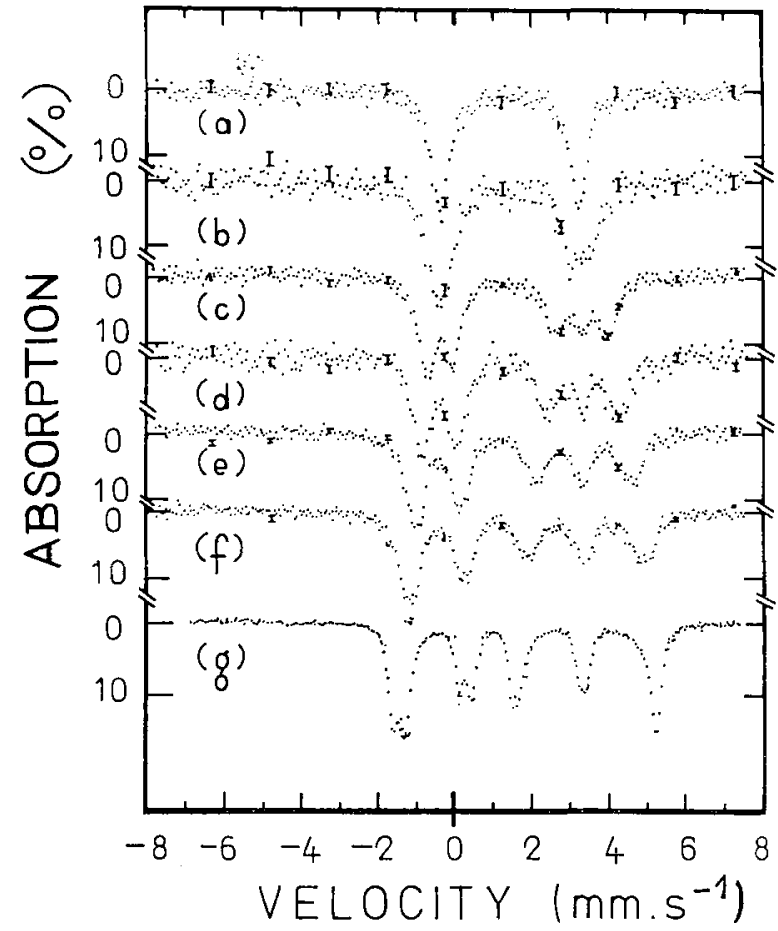

FIG. 4. - Mössbauer spectra of polycrystalline ferrous fluosilicate $\mathrm{FeSiF}_{6} .6 \mathrm{H}_{2} \mathrm{O}$ at $4.2 \mathrm{~K}$ in magnetic fields of $(a) 0 \mathrm{kOe}$; (b) $4.5 \mathrm{kOe}$; (c) $10.5 \mathrm{kOe}$; (d) $15 \mathrm{kOe}$; (e) $21 \mathrm{kOe}$; (f) $30 \mathrm{kOe}$ and $(g) 60$ kOe.

$\mathrm{Fe}^{2+}$ may be estimated to be $4 / 5$ of the $\mathrm{Fe}^{3+}$ field, i. e. $H_{\mathrm{s}}=-315 \mathrm{kOe}$. The dipolar field $H_{\mathrm{dx}}$ is about +64 kOe. From the value of $D, g_{\perp}$ is estimated to be 2.04, and hence the orbital field $H_{\mathrm{Lx}}=+36 \mathrm{kOe}$. Adding these values together.

$$
\begin{aligned}
& H_{\mathrm{s}}=-315 \mathrm{kOe} \\
& H_{\mathrm{dx}}=+64 \mathrm{kOe} \\
& H_{\mathrm{Lx}}=+36 \mathrm{kOe}
\end{aligned}
$$

gives an expected total for $H_{\mathrm{nx}}\left(\mathrm{Fe}^{2+}\right)$ of $-215 \mathrm{kOe}$, which agrees well with the measured value of -210 kOe.

3.2 2-IRON PROTEINS (PLANT-TYPE FERREDOXINS). At $77 \mathrm{~K}$ the Mössbauer spectrum of the oxidized proteins consists of a doublet, while on reduction two doublets are observed, one due to $\mathrm{Fe}^{2+}$ and one due to $\mathrm{Fe}^{3+}[10]$. In both states the iron atoms are believed to be coupled together antiferromagnetically. When oxidized there are two $\mathrm{Fe}^{3+}$ atoms and their total spin is zero, which agrees with their temperature independent susceptibility. On reduction one electron is transferred to the molecule so that one $\mathrm{Fe}^{3+}$ is converted to $\mathrm{Fe}^{2+}$ while the other remains unchanged. The coupling between the $\mathrm{Fe}^{3+}$ atom (with $S_{1}=5 / 2$ ) and the $\mathrm{Fe}^{2+}$ atom (with $S_{2}=2$ ) results in a ground state with total spin $S=S_{1}+S_{2}=1 / 2$. This model was proposed to account for the unusual $g$-values centred around 1.94 found from the EPR spectra of these molecules [11]. Figure 5 shows the way the spins $S_{1}$ and $S_{2}$ couple together to give the resultant $S$.

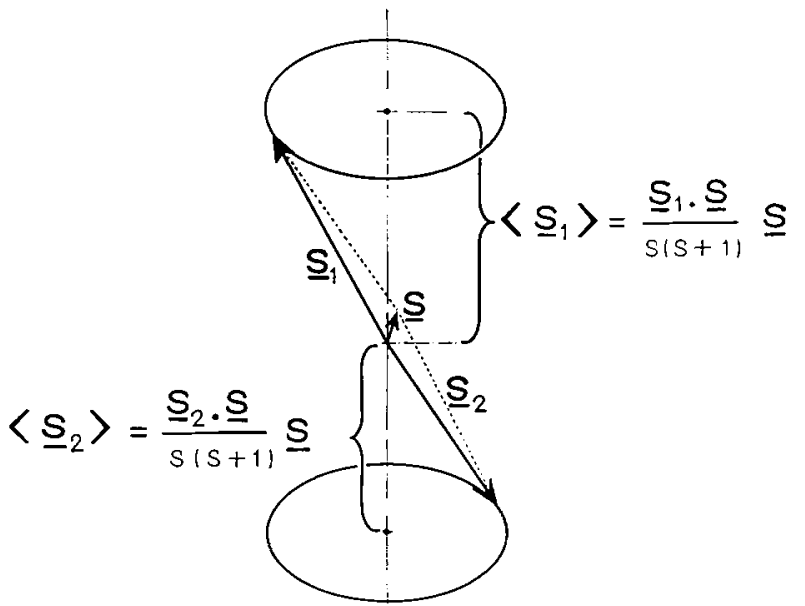

FIG. 5. - Antiferromagnetic coupling of spins $S_{1}$ and $S_{2}$ to give a resultant $S=S_{1}+S_{2}$. In an applied field $S_{1}$ and $S_{2}$ are decoupled and precess about the field, so that their components along the field are $\left\langle S_{1}\right\rangle$ and $\left\langle S_{2}\right\rangle$.

At low temperatures (e. g. $4 \mathrm{~K}$ ) the Mössbauer spectrum of the reduced protein shows magnetic hyperfine splitting because the electron spin-lattice relaxation time has become long compared with hit where $A$ is the hyperfine coupling. The spins $S_{1}$ and $S_{2}$ precess about their resultant $S$ and the observed spectrum is asymmetrical and has broad and partly resolved lines. When a small magnetic field $H>A S \mathrm{~g} g \beta$ is applied a more symmetrical spectrum with shalrper lines results. The effect of the field is to cause $S_{1}$ and $S_{2}$ to precess about it and this results in two separate effective magnetic fields at the nuclei. The resulting spectrum is a superposition of two contributions. one from $\mathrm{Fe}^{3+}$ and one from $\mathrm{Fe}^{2+}$ and the lines from each are strongly overlapping.

On increasing the size of the applied field the spectrum splits into two components, showing that $H_{12}$ and $H_{2 z}$ have different signs owing to the antiferromagnetic coupling between the two iron atoms. This is shown in figure 6 for adrenodoxin [12]. At $1.7 \mathrm{~K}$ the population of the $S_{z}=+1 / 2$ state is small $(9 \%)$ and the lines due to $\mathrm{Fe}^{3+}$ and $\mathrm{Fe}^{2+}$ can be sepallated out as shown. Although the use of stick diagrams is not strictly valid when the hyperfine interation tensor is anisotropic, it has been shown that they can give a remarkably good approximation to the observed spectrum for many $\mathrm{Fe}^{2+}$ salts [\&]. On warming the samples to $4.2 \mathrm{~K}$ the $S_{7}=+1: 2$ state becomes appreciably populated $(28$ ") and contributes extra lines to the spectrum (See Fig. $6\left(\right.$ a) $\mathrm{com}^{-}$ pared with $(b))$.

The separation of the spectrum due to the ground state $\mid S_{\mathrm{z}}=-1 / 2>$ from the excited stite $\left|S_{z}=+1 / 2\right\rangle$ is carried out by subuacting the $1.7 \mathrm{~K}$ spectrum $\left(S_{1.7}\right)$ from that measured at $4.2 \mathrm{~K}$ $\left(S_{4.2}\right)$, suitably weighting each according to their populations at these temperatures. Thus the upper spectrum of ligure 7 is the contribution from the 


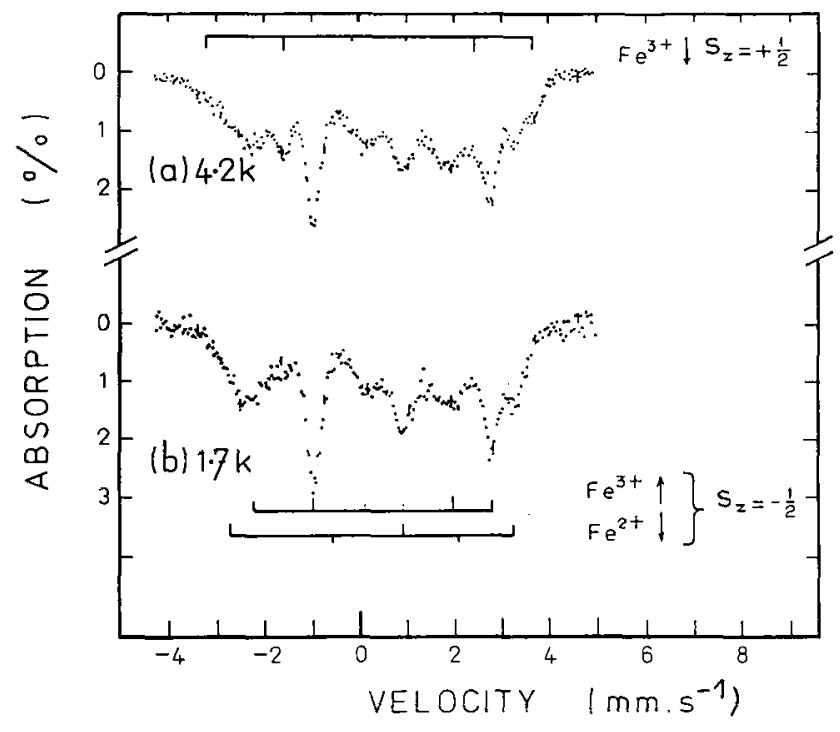

FIG. 6. - Mössbauer spectra of reduced adrenodoxin in $30 \mathrm{kOe}$ applied perpendicular to the '--ray beam at (a) $4.2 \mathrm{~K}$ and (b) $1.7 \mathrm{~K}$. The lower stick diagrams show the lines which can be identified at $1.7 \mathrm{~K}$ due to the $S_{\mathrm{z}}=-1 / 2$ state. The upper diagram shows the extra lines which appear at $4.2 \mathrm{~K}$ due to the population ( $28 \%$ ) of the $S_{\mathrm{z}}=+1 / 2$ state.

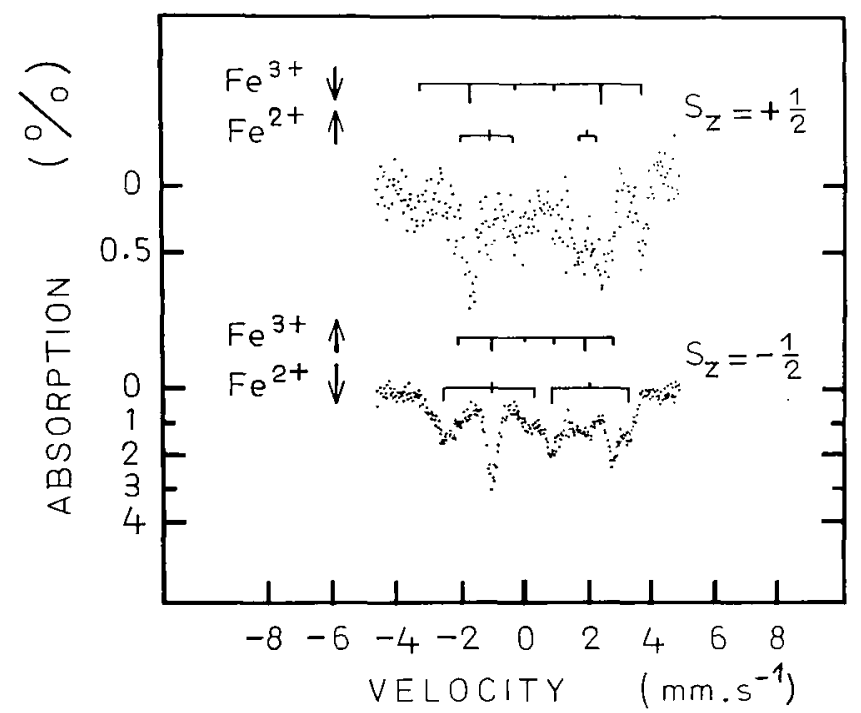

FIG. 7. - Mössbauer spectra in an external field of $30 \mathrm{kOe}$ of the $S_{\mathrm{z}}+=1 / 2$ and $S_{\mathrm{z}}=-1 / 2$ states of adrenodoxin, derived from the data of figure 6 .

excited state, and is constructed by taking $4.82 S_{4.2}-3.82 S_{1.7}$ while the lower spectrum is that due to the ground state which is given by $1.45 S_{1.7}-0.45 S_{4.2}$.

The Mössbauer spectrum therefore allows the antiferromagnetic coupling between the $\mathrm{Fe}^{2+}$ and $\mathrm{Fe}^{3+}$ atoms in reduced 2 -iron proteins to be confirmed: Atoms with spins pointing up (i. e. parallel to the resultant spin $S$ ) have the effective field at the nucleus reduced by the external field (since the hyperfine field is negative), so that their spectrum is compressed by the field. On the other hand atoms with spins dow'n have their effective field increased, i. e. the spectrum appears to expand in the external field. However it is not easy to identify all the lines, especially those due to $\mathrm{Fe}^{2+}$, from the Mossbauer spectrum alone. The hyperfine interaction tensor for the $\mathrm{Fe}^{2+}$ atoms has been measured [13] in some of these proteins using ENDOR, and from these data the Mössbauer Spectra of spinach ferredoxin [14] and putidaredoxin [15] have been interpreted in detail.

Because of the coupling between the two atoms the effective field at their nuclei is reduced from the values in the free atoms, and is about $180 \mathrm{kOe}$ for $\mathrm{Fe}^{3+}$ and very roughly $120 \mathrm{kOe}$ for $\mathrm{Fe}^{2+}$. This may be understood as follows. The fields are proportional to the projections $\left\langle S_{1}\right\rangle$ and $\left\langle S_{2}\right\rangle$ of their spins along the total spin $S$, i. e.

$$
H_{1 z}=\frac{<S_{1}>}{S_{1}} H_{n z}\left(\mathrm{Fe}^{3+}\right)
$$

and

$$
H_{2 \mathrm{z}}=\frac{<S_{2}>}{S_{2}} H_{\mathrm{nz}}\left(\mathrm{Fe}^{2+}\right)
$$

where $H_{\mathrm{nz}}\left(\mathrm{Fe}^{3+}\right)$ and $H_{\mathrm{nz}}\left(\mathrm{Fe}^{2+}\right)$ are components of the hyperfine field tensor for the uncoupled ferric and ferrous ions respectively. The projections of the $S_{1}$ and $S_{2}$ upon $S$ are (see Fig. 5)

$$
<S_{1}>=\frac{S_{1} \cdot S}{S}=\frac{S_{1} \cdot S}{S(S+1)}<S>=\frac{7}{3}<S>
$$

and

$$
\begin{aligned}
& <S_{2}>=\frac{S_{2} \cdot S}{S}=\frac{S_{2} \cdot S}{S(S+1)}<S>=-\frac{4}{3}<S> \\
& \qquad H_{1 z}=\frac{7}{3} \frac{<S>}{S_{1}} H_{\mathrm{nz}}\left(\mathrm{Fe}^{3+}\right)=\frac{7}{15} H_{\mathrm{nz}}\left(\mathrm{Fe}^{3+}\right)
\end{aligned}
$$
so

and

$$
H_{2 z}=-\frac{4}{3} \frac{<S>}{S_{2}} H_{\mathrm{nz}}\left(\mathrm{Fe}^{2+}\right)=-\frac{1}{3} H_{\mathrm{nz}}\left(\mathrm{Fe}^{2+}\right)
$$

since $\langle S\rangle=S=1 / 2$.

For the $\mathrm{Fe}^{3+}$ atom $H_{\mathrm{n}}$ will be approximately isotropic, and taking the value found in oxidized rubredoxin, one would expect $H_{1 \mathrm{z}}=-185 \mathrm{kOe}$, in good agreement with the observed value of about $-180 \mathrm{kOe}$. For the $\mathrm{Fe}^{2+}$ ion the hyperfine field is anisotropic and we need to estimate $H_{\mathrm{nz}}\left(\mathrm{Fe}^{2+}\right)$ using the value of $H_{n x}\left(\mathrm{Fe}^{2+}\right)$ measured in reduced rubredoxin. Taking the value for $H_{\mathrm{s}}$ found in reduced rubredoxin, and estimating $H_{\mathrm{Lz}}(+40 \mathrm{kOe})$ from the value of $g_{\mathrm{z}}$ and $H_{\mathrm{dz}}\left(-128 \mathrm{kOe}\right.$ for the $d_{z^{2}}$ orbital ground state), we have

$$
\begin{aligned}
& H_{\mathrm{s}}=-315 \mathrm{kOe} \\
& H_{\mathrm{dz}}=-128 \mathrm{kOe} \\
& H_{\mathrm{Lz}}=+40 \mathrm{kOe}
\end{aligned}
$$


so that

$$
H_{\mathrm{nz}}\left(\mathrm{Fe}^{2+}\right)=-403 \mathrm{kOe} .
$$

Thus $H_{2 z}$ should be $+135 \mathrm{kOe}$, again agreeing with the measured value of about $120 \mathrm{kOe}$.

3.3 4-AND 8-IRON PROTEINS. - As well as in the 2-iron proteins, magnetic coupling exists between iron atoms in iron-sulphur proteins containing more than 2-iron atoms. These proteins include the bacterial ferredoxins, which may contain 4-iron atoms per molecule (e. g. Bacillus ferredoxin) or 8-iron atoms (e. g. from Clostridium Pasteurianum or Chromatium) the high potential iron proteins (HIPIPs) (4-iron atoms per molecule), and the conjugated iron-sulphur proteins (flavoproteins, iron-molybdenum proteins, etc.) which contain 8 or more iron atoms per molecule.

The bacterial ferredoxins have many features in common with the simpler plant-type ferredoxins; they are non-magnetic when oxidized and have negative redox potentials, becoming magnetic with an average $g$-value less than 2 when reduced by the transfer of one electron per molecule. Their Mössbauer (and EPR) spectra show a considerably more complex behaviour than the 2 -iron proteins. This of course is hardly surprising as there is a large number of ways that more than two atoms can be magnetically coupled together. The molecular structure of one of the 8-iron proteins has been determined and shows that the iron is in units containing 4-iron atoms close together, but their Mössbauer spectra have not yet been completely interpreted. Distinct quadrupole doublets corresponding to $\mathrm{Fe}^{3+}$ and $\mathrm{Fe}^{2+}$ states are not observed in their high temperature Möss- bauer spectra, as they are for the 2-iron proteins. At low temperatures, however. magnetic hyperfine splitting is observed in the spectra of the reduced protein and when an external magnetic field is applied, both positive and negative hyperfine fields are observed. Thus Mössbauer data provides evidence for antiferromagnetic coupling between the iron atoms in bacterial as well as plant-type ferredoxins.

The HIPIPs have 4-iron atoms per molecule all close together in a cluster. They have positive redox potentials and are non-magnetic in the reduced state, but they lose one electron per molecule when oxidized and become magnetic with an average $g$-value greater than 2. As with the reduced bacterial ferredoxins, the Mössbauer spectra in the reduced state do not show distinct contributions from $\mathrm{Fe}^{3+}$ and $\mathrm{Fe}^{2+}$ states, but they show both positive and negative hyperfine fields $i$. e. the iron atoms are again antiferromagnetically coupled together in these proteins.

Xanthine oxidase is a flavoprotein which contains 1-molybdenum and 8-iron atoms in a molecule of molecular weight about 275000 . Its redox potential is negative, and it is non-magnetic in the oxidized state and magnetic when reduced with an average g-value below 2. This was the first iron-sulphur protein in which magnetic hyperfine spliting was observed [16] by Mössbauer spectroscopy, and the behaviour seemed most closely to resemble the plant-type ferredoxins, i. e. in the reduced state separate $\mathrm{Fe}^{3+}$ and $\mathrm{Fe}^{2+}$ spectra were observed at high temperaltures. Presumably the 8-iron atoms in the molecule are in four pairs, each pair being in a unit which resembles the active centre in the plant-type ferredoxins.

\section{References}

[1] Gonser, U., Proc. 2nd Int. Conf. on Mössbauer Effect, Paris (Wiley) 1962 p. 280.

[2] Lang, G. and Marshall, W., Proc. Phys. Soc. 87 (1966) 3.

[3] Winter, M. R. C., Johnson, C. E., LANG, G. and WilLIAMS, R. J. P., Biochim. Bioply's. Acta 263 (1972) 515.

[4] Lang, G., Quart. Rev. Biophys. 3 (1970) 1.

[5] Tsibris, J. C. M., and Woody, R. W., Co-ordination Chemistry Reviews (Elsevier 1969).

[6] Phillips, W. D., Poe, M., Weiher, J. F., McDonald, C. C. and Lovenberg, W., Nature 227 (1970) 574.

[7] Rao, K. K., Evans, M. C. W., Cammack, R., Hall, D. O., Thompson, C. L., JACKSON, P. J. and Johnson, C. E., Biochem. J. 129 (1972) 1063.

[8] Johnson, C. E., Proc. Phys. Soc. 92 (1967) 748.
[9] Marshall, W. and Johnson, C. E., J. Phrsique Rull. 23 (1962) 733.

[10] Rao, K. K., Cammack, R., Hall, D. O. and Johnson, C. E., Biochem. J. 122 (1971) 257.

[11] Gibson, J. F., Hall, D. O., Thornley, J. H. M. and Whatley, F. R., Proc. Nat. Acad. Sci. US 56 (1966) 987.

[12] Cammack, R., Rao, K. K., Hall, D. O. and Johnson C. E., Biochem. J. 125 (1971) 849.

[13] Fritz, J., et al., Biochem. Biophys. Acta 253 (1971) 110.

[14] Dunham, W. R. et al., Biochem. Biophys, Acta 253 (1971) 134.

[15] Munck, E., Debrunner, P. G., Tsibris, J. C. M. and Gunsalus, I. C., Biochem. J. 11 (1972) 855.

[16] Johnson, C. E., Knowles, P. F. and Bray, R. C., Biochem. J. 103 (1967) 10C. 